\title{
Conserved loci of leaf and stem rust fungi of wheat share synteny interrupted by lineage-specific influx of repeat elements
}

\author{
John P Fellers ${ }^{1 *}$, Bahram M Soltani ${ }^{2}$, Myron Bruce $^{1}$, Rob Linning ${ }^{2}$, Christina A Cuomo ${ }^{3}$, Les J Szabo ${ }^{4}$
} and Guus Bakkeren ${ }^{2}$

\begin{abstract}
Background: Wheat leaf rust (Puccinia triticina Eriks; $P t)$ and stem rust fungi (P. graminis f.sp. tritici; Pgt) are significant economic pathogens having similar host ranges and life cycles, but different alternate hosts. The Pt genome, currently estimated at $135 \mathrm{Mb}$, is significantly larger than Pgt, at $88 \mathrm{Mb}$, but the reason for the expansion is unknown. Three genomic loci of Pt conserved proteins were characterized to gain insight into gene content, genome complexity and expansion.

Results: A bacterial artificial chromosome (BAC) library was made from P. triticina race 1, BBBD and probed with Pt homologs of genes encoding two predicted Pgt secreted effectors and a DNA marker mapping to a region of avirulence. Three BACs, $103 \mathrm{~Kb}, 112 \mathrm{~Kb}$, and $166 \mathrm{~Kb}$, were sequenced, assembled, and open reading frames were identified. Orthologous genes were identified in Pgt and local conservation of gene order (microsynteny) was observed. Pairwise protein identities ranged from 26 to 99\%. One Pt BAC, containing a RAD18 ortholog, shares syntenic regions with two Pgt scaffolds, which could represent both haplotypes of Pgt. Gene sequence is diverged between the species as well as within the two haplotypes. In all three BAC clones, gene order is locally conserved, however, gene shuffling has occurred relative to Pgt. These regions are further diverged by differing insertion loci of LTR-retrotransposon, Gypsy, Copia, Mutator, and Harbinger mobile elements. Uncharacterized Pt open reading frames were also found; these proteins are high in lysine and similar to multiple proteins in Pgt.
\end{abstract}

Conclusions: The three Pt loci are conserved in gene order, with a range of gene sequence divergence. Conservation of predicted haustoria expressed secreted protein genes between Pt and Pgt is extended to the more distant poplar rust, Melampsora larici-populina. The loci also reveal that genome expansion in $P t$ is in part due to higher occurrence of repeat-elements in this species.

Keywords: Wheat leaf rust, BAC construction, Synteny

\section{Background}

Plants and pathogens are in a constant struggle as each co-evolves to adapt to genomic changes. Plant genomes are adapting to different modes of infection by pathogens while pathogens are evolving different avenues to circumvent defense systems of their respective hosts. Rust fungi are among the most economically important pathogens, yet are part of elusive host-pathogen systems. The order

\footnotetext{
*Correspondence: john.fellers@ars.usda.gov

'USDA-ARS, Hard Winter Wheat Genetics Research Unit, Department of Plant Pathology, Manhattan, KS 66506, USA

Full list of author information is available at the end of the article
}

Pucciniales (formerly Uredinales or Urediniomycetes) contains over 7,000 different species from 100 genera [1]. Adding to the complexity, individual cereal crops can be infected by several rust fungi adapted to the specific crop.

Cereal rust fungi are obligate biotrophs and have alternate hosts where sexual recombination takes place, allowing for diversification of the population [2]. The life cycle of cereal rust fungi begins with a urediniospore landing on a leaf surface and germinating in the presence of adequate humidity. A germtube emerges and moves towards a stomate via a thigmotrophic response and probable chemical clues [3] where an appressorium will
Ciomed Central

(c) 2013 Fellers et al.; licensee BioMed Central Ltd. This is an Open Access article distributed under the terms of the Creative Commons Attribution License (http://creativecommons.org/licenses/by/2.0), which permits unrestricted use, distribution, and reproduction in any medium, provided the original work is properly cited. 
form. A hypha grows inside the substomatal space until a mesophyll cell is encountered. The fungus will penetrate the cell wall and produce a haustorium by invagination of the plasma membrane [4,5] At each stage of infection, the fungus is postulated to secrete effectors to inhibit cell defenses and reprogram cells to redirect nutrients. Though some candidate effectors are shared among the rust fungi, most are specific to their host and include transcription factors, zinc finger proteins, small secreted proteins and cysteine-rich proteins [6]. Certain classes of effectors, such as ones modulating host immunity, are believed to rapidly change to overcome resistance, however, the mechanisms generating this variation are not known. In several studied pathogens, certain classes of predicted effectors are found in variable and highly mutagable regions of the genome. Mobile elements induced mutations in effectors in Phytophthora [7], Magnaporthe [8], and Leptosphaeria [9] while Fusarium oxysporum has a specialized chromosome with effectors $[10,11]$. Effectors can be clustered in the genome (Ustilago; [12]) including at telomeres (Fusarium, [13]; Magnaporthe; [14]). Avirulence genes from the flax rust fungus, Melampsora lini are all small secreted proteins [15,16]. Currently, two effectors have been identified in urediniospores of Puccinia graminis f.sp. tritici (Pgt) that induce the in vivo phosphorylation and degradation of the barley resistance protein, RPG1 [17].

Sequencing technology has made significant advancements in recent years. Complete genomes of more species, including fungi, are being sequenced. Comprehensive catalogs of genes can be generated, annotated, and comparisons made to other genomes. Core sets of genes needed for function, adaptations for life cycle, and host specificity can now be found. Comparisons of several obligate fungal plant parasites have identified common losses of genes involved in nitrate and sulfur metabolism [6,18]. Melampsora larici-populina ( $M l p)$ and Pgt have approximately 8,000 orthologous genes which could be suggested as a core set needed for biotrophism. However, $74 \%$ and $84 \%$ of the secreted proteins, respectively, are lineage specific [6] suggesting proteins that are needed for the individual life cycle. Corn pathogens, $U$. maydis and $S$. reilianum are also closely related and share $71 \%$ of effector genes in so-called divergence clusters. However, $10 \%$ are $U$. maydis specific while $19 \%$ are specific to $S$. reilianum [19].

Puccinia triticina $(P t)$ is the causal agent of wheat leaf rust and new races emerge each year aided by a crop monoculture placing a strong selection pressure on the pathogen. Genetic variation is generally believed to increase through sexual recombination to generate new allele combinations. Two related wheat rust fungi, Pgt and P. striiformis f.sp. tritici (Pst), causing stripe rust, have a sexual cycle on North American Berberis spp. and have a greater race variability where the alternate host is present [20]. The Pt aeciospore stage is on Thalictrum spp. and Isopyrum, found mainly in the Mediterranean region, however, other Thalictrum species present in North America can support a reduced level of infection [21] but are generally resistant to Pt [22,23]. Populations are essentially asexual; supported by the lack of recombination found in numerous North American races [24-28]. A parasexual cycle may exist allowing recombination since germtube fusion, nuclear migration, and bridging structures between nuclei have been observed in Pt [29].

The obligate biotrophic nature of cereal rusts makes experimental manipulation difficult, however, genomics provides a means of studying evolution and gene function. We set out to understand the genome variation of two rust fungi at three regions. A Pt bacterial artificial chromosome (BAC) library was made and clones were identified using three probes that would isolate regions of predicted secreted proteins and avirulence. Sequenced DNA regions of $P t$ were compared to syntenic regions in two rust species with complete genome sequences, Pgt, and $M l p$ [6], and evaluated for genomic conservation, expansion and mutations.

\section{Results}

\section{BAC library construction}

Urediniospores harbor two haploid nuclei with an estimated total genome complexity for Pt of approximately $135 \mathrm{Mb}$, based on comparative DNA fluorescence (L. Szabo, unpublished) and the current total size of the genome assembly (http://www.broadinstitute.org/ annotation/genome/puccinia_group/GenomeStats.html). The generated P. triticina BAC library contained 15,360 clones arrayed in 384 well plates with an average insert size of $105 \mathrm{~kb}$ representing an estimated 10 to 12 genome equivalents. A single-copy probe identified nine positive clones on high density filters, and assuming fragments were randomly cloned during library construction, this is in agreement with the estimated genome coverage.

\section{BAC clone selection, sequencing and characterization}

Three genomic regions were targeted for comparison. Previous work had mapped a Pgt RAD18 homolog in a genomic region harboring an avirulence gene [30]. Using PgtRAD18 as a reference, PT0313.J16.C21 (GenBank accession number GR497566) was identified from a $P t$ EST database using TBLASTN (E value =e-107; [31,32]) and used as a probe. Nine positive BAC clones were found and clone 1F16 (Pt1F16) was selected for sequencing because of its longer length and the centralized location of PtRAD18 within the BAC clone. Sequences from Pt1F16 were assembled into two contiguous sequences of 39,219 and 63,874 bp, totaling 103,093 bp (GenBank JX489506). The GC content of these sequences was $47 \%$. Subclones 
were generated spanning the gap for orientating and ordering of the two contigs. However, due to a region of 60 near-perfect 46 bp repeats of ACCAGCCCGCCGAGAG GAAGCCCTCTCGGCGAGCTGGTGTGTGTAT, the gap could not be closed. FGENESH, with gene models from the Puccinia group genome project (http://www.broad institute.org/annotation/genome/puccinia_group/), predicted 30 open reading frames (ORFs) ranging from 210 to $4,077 \mathrm{bp}$ in length.

In a functional screen of Uromyces viciae-fabae, secreted peptide effector protein UF5 was related to the flax rust Melampsora lini haustorial-expressed secreted protein HESP-379 [16]. A Pgt genome search revealed several predicted secreted protein homologs in close proximity, suggesting the presence of small clusters of predicted secreted proteins. UF5 (Genbank ES608162) aligned with two predicted secreted proteins, PGTG_03708 (E score $5 \mathrm{e}^{-33}$ ) and PGTG_03709 (E score 0), both transcribed and located $513 \mathrm{bp}$ apart on the Pgt contig. Using these Pgt sequences, PtContig18 (Genbank accession HP451841) and PtContig7347 (Genbank accession HP458556) were identified by a BLASTN P $t$ EST database search. A PCR product from the cDNA clone, Pt EST PT0061b.D10.TB that aligned to Contig18 (GenBank accession EC400508), was used as a probe to identify Pt BAC PtHSP02. Sequencing of this BAC resulted in four assembled contigs. Gaps could be spanned and thus the contigs could be ordered and oriented. Sizes of the contigs in bp were $16,991,30,055,5,014$, and 60,277 for a total of 112,337 bp (GenBank JX489507). Gaps were present in regions of repeated DNA and could not be assembled. GC content was $46.3 \%$ and FGENESH predicted $31 \mathrm{ORFs}$ in the contig ranging from $174 \mathrm{bp}$ to $7,167 \mathrm{bp}$ in length. The smaller ORFs were generally within repeated elements.

The bean rust effector UfHSP42c Uf011 (GenBank ES608167; [33]) matched three predicted protein sequences in Pgt, PGTG_17547 (E Score 0), PGTG_17548 (E Score 1 $\left.\mathrm{e}^{-21}\right)$ and PGTG_17549 (E Score $\left.1 \mathrm{e}^{-4}\right)$. UfHSP42c matched five Pt ESTs, including clone PT0131d.B10.BR (GenBank accession EC414978) from which probes were derived to identify Pt BAC clone HSP04. Sequencing of HSP04 produced two contiguous sequences of 9,276 bp and 157,027 bp for a total of 166,303 bp (GenBank JX489508). GC content was $46.3 \%$ and 61 ORFs were predicted ranging from $120 \mathrm{bp}$ to $5,214 \mathrm{bp}$ in length.

\section{BAC annotation}

The predicted ORFs from each BAC clone were aligned using BLASTN to the Pgt genome, Pgt predicted transcripts and Pt ESTs, and using BLASTX, to the Pgt, $M l p$, and $U$. maydis (Um) predicted proteomes (Table 1). Pt1F16 had nine ORFs with synteny in Pgt. Identity across the protein sequences ranged from $37-87 \%$ in these alignments and putative annotations could be assigned to five of the proteins. Pt1F16-4 contained many gaps when compared to PGTG_13013. Proteins Pt1F16-5, 6, 7, 8 and 9 aligned with two proteins each from Pgt. Pt1F16-7 aligned with PgtRAD18, which has one copy in each of the Pgt haplotype genomes. All but one homolog could also be found in $M l p$ and four were represented in $U m$ (Table 1).

Nine predicted proteins in PtHSP02 were confirmed through EST sequence alignment [32] and a putative function could be assigned to eight of them. Alignment identity ranged from $30-100 \%$ in PtHSP02. Eight homologs could be found in both $M l p$ and $U m$ in PtHSP02. The most highly conserved protein is PtHSP02-6, a G-protein ßsubunit containing a conserved WD-40 repeat motif. The first 343 amino acids were 100\% identical to PGTG_03727 and $99 \%$ to Mlp accession GL883091 (Table 1). Conversely, PtHSP02-3 was only 30\% identical to PGTG_3706 and had no homologs in the other two fungi. PtHSP02-4 and PtHSP02-5 aligned with Mlp HESP-379, the haustorial expressed predicted secreted protein homolog from M. lini, and a homolog was found for each in Pgt (Table 1, Figure 1). Two insertions/deletions were found in PtHSP02-4 and PGTG_3708 (Figure 1A). PtHSP02-5 and PGTG_3709 aligned to homologs from M. lini, Mlp, M. medusae deltoidis, and $U$. maydis. The $\mathrm{N}$-terminal half of the protein was conserved between Puccinia and Melampsora (Figure 1B). There appeared to be 48 genus-specific amino acid changes across the protein. Um was the most diverged with only a few conserved motifs.

Fourteen predicted proteins were identified in PtHSP04 and could be supported through EST sequence alignment. Every protein had a homolog in Pgt with protein identities ranging from $26-95 \%$ (Table 1); nine could be assigned a putative function. Eight PtHSP04 proteins had homologs in $M l p$ and five in Um. PtHSP04-1, 5, and 14 appeared to be unique to $P t$ with little homology to Pgt. The predicted transcripts of PtHSP04-6, 7, 8 and 9 aligned to a single EST of $P$. striiformis predicted to encode a secreted protein (ADA54575; [34]) at scores of $4 \mathrm{e}^{-5}, 2 \mathrm{e}^{-8}, 6 \mathrm{e}^{-48}$, and $3 \mathrm{e}^{-9}$, respectively. PtHSP04- 6 and 7 aligned both to PGTG_17549, though revealing 26 and 60\% identity, respectively. The predicted HSP04-7 ORF is 1,095 bp in length and contains a 3' in-frame repeat of nine nucleotides, $\mathrm{GG}(\mathrm{C} / \mathrm{T}) \mathrm{AC}(\mathrm{T} / \mathrm{A}) \mathrm{AC}(\mathrm{T} / \mathrm{A})$, translating to 30, three amino acid repeats of Gly-Thr-Thr. Without the repeat, PtHSP04-7 is a homolog to PGTG_17549, while PtHSP046 is unique to Pt. PtHSP04-8 and 9 are responsible for the homology to Uf-HSP42c and isolation of the BAC clone (Figure 2, Table 1). They are very highly identical except for the C-terminal 18 amino acids, where PtHSP04-9 has a five amino acid deletion and only four identities (Figure 2). Each aligned to PGTG_17547 and PGTG_17548, adjacent proteins which themselves are 100\% identical. PtHSP04-8 
Table 1 Gene features in three Puccinia triticina BAC clones and their alignment to other sequenced Basidiomycetes, P. graminis tritici (Pgt), Melampsora larici-populina (MIp), and Ustilago maydis (Um)

\begin{tabular}{|c|c|c|c|c|c|}
\hline $\begin{array}{l}\text { P. triticina } \\
\text { ORF }\end{array}$ & $\begin{array}{l}\text { Pgt Gencxxe } \\
\text { Feature* }\end{array}$ & $\begin{array}{l}\text { Pgt protein } \\
\text { identities }\end{array}$ & $\begin{array}{l}M l p \\
\text { gene feature }{ }^{* *}\end{array}$ & $\begin{array}{l}\text { Um } \\
\text { gene feature }\end{array}$ & $\begin{array}{l}\text { BLASTX } \\
\text { Annotation }\end{array}$ \\
\hline 1 F16-1 & PGTG_12990 & $54 \%$ & $35.90208 / 11$ & - & Similar to Uhrf1 \\
\hline 1 F16-2 & PGTG_13012 & $60 \%$ & 104.11397 & Um_00786 & Hypothetical protein \\
\hline 1 F16-3 & PGTG_13013 & $63 \%$ & 74. 94858 & - & Similar to esterase \\
\hline \multirow[t]{2}{*}{1 F16-4 } & PGTG_13016 & $37 \%$ & \multirow[t]{2}{*}{-} & \multirow[t]{2}{*}{-} & \multirow[t]{2}{*}{ Predicted protein } \\
\hline & PGTG_18731 & $64 \%$ & & & \\
\hline \multirow[t]{2}{*}{1 F16-5 } & PGTG_13018 & $67 \%$ & \multirow[t]{2}{*}{49.39112} & \multirow[t]{2}{*}{ Um_02725 } & \multirow{2}{*}{$\begin{array}{l}\text { Similar to molybdopterin } \\
\text { synthase sulpherylase }\end{array}$} \\
\hline & PGTG_18732 & $68 \%$ & & & \\
\hline \multirow[t]{2}{*}{1 F16-6 } & PGTG_13021 & $68 \%$ & \multirow[t]{2}{*}{74.73436} & \multirow[t]{2}{*}{-} & \multirow[t]{2}{*}{ Hypothetical protein } \\
\hline & PGTG_18735 & $64 \%$ & & & \\
\hline \multirow[t]{2}{*}{1 F16-7 } & PGTG_13023 & $56 \%$ & \multirow[t]{2}{*}{74.94864} & \multirow[t]{2}{*}{ Um_05085 } & \multirow[t]{2}{*}{ RAD18 } \\
\hline & PGTG_18741 & $56 \%$ & & & \\
\hline \multirow[t]{2}{*}{1 F16-8 } & PGTG_13024 & $64 \%$ & \multirow[t]{2}{*}{74.000024} & \multirow[t]{2}{*}{-} & \multirow{2}{*}{$\begin{array}{l}\text { cystein rich SCP-like } \\
\text { extracellular protein }\end{array}$} \\
\hline & PGTG_18744 & $65 \%$ & & & \\
\hline \multirow[t]{2}{*}{1 F16-9 } & PGTG_13026 & $87 \%$ & \multirow[t]{2}{*}{$74.50754 / 28052$} & \multirow[t]{2}{*}{ Um_00594 } & \multirow{2}{*}{$\begin{array}{l}\text { Similar to pyruvate } \\
\text { dehydrogenase complex }\end{array}$} \\
\hline & PGTG_18746 & $86 \%$ & & & \\
\hline HSP02-1 & PGTG_3730/1 & $79 \%$ & 22.87674 & Um_00736 & Conserved protein \\
\hline HSPO2-2 & PGTG_6672 & $48 \%$ & 68.40205 & Um_04270 & Aspartyl-tRNA synthetase \\
\hline HSP02-3 & PGTG_3706 & $30 \%$ & - & - & - \\
\hline $\mathrm{HSPO2-4}$ & PGTG_3708 & $69 \%$ & 2.70587 & Um_01555 & MIp HESP-379 \\
\hline HSP02-5 & PGTG_3709 & $83 \%$ & 2.70587 & Um_01555 & Mlp HESP-379 \\
\hline HSP02-6 & PGTG_3727 & $100 \%$ & 2.76428 & Um_00703 & G-protein beta subunit \\
\hline HSP02-7 & PGTG_3728 & $68 \%$ & 2.115002 & Um_03486 & Nucleotide-binding protein 2 \\
\hline HSP02-8 & PGTG_3729 & $82 \%$ & 2.46419 & Um_05743 & $\begin{array}{l}\text { Pre-mRNA splicing factor ATP- } \\
\text { dependent } \\
\text { RNA helicase PRP16 }\end{array}$ \\
\hline HSP02-9 & PGTG_3730 & $87 \%$ & 10.115914 & Um_04551 & Similar to cyclin Ctk2 \\
\hline HSP04-1 & PGTG_16978 & $36 \%$ & - & - & Predicted protein \\
\hline HSP04-2 & PGTG_16976 & $73 \%$ & 27.88522 & Um_00639 & Nucleoporin-like \\
\hline HSP04-3 & PGTG_10949 & $95 \%$ & 47.72927 & Um_02479 & 605 ribosomal protein \\
\hline HSP04-4 & PGTG_02586 & $33 \%$ & 27.88520 & - & Heat shock protein 90 \\
\hline HSP04-5 & PGTG_14539 & $41 \%$ & - & - & Predicted protein \\
\hline HSP04-6 & PGTG_17549 & $26 \%$ & - & - & Predicted secreted protein \\
\hline HSP04-7 & PGTG_17549 & $60 \%$ & - & - & Predicted secreted protein \\
\hline HSP04-8 & PGTG_17547/8 & $76 \%$ & 16.85997 & - & Uf-HSP42C \\
\hline HSP04-9 & PGTG_17547/8 & $71 \%$ & 16.85997 & - & Uf-HSP42C \\
\hline HSP04-10 & PGTG_05205 & $82 \%$ & 22.48630 & - & Integral membrane protein \\
\hline HSP04-11 & PGTG_17545 & $52 \%$ & - & Um_00662 & Predicted protein \\
\hline HSP04-12 & PGTG_17544 & $83 \%$ & 23.87824 & Um_03820 & Vacuolar sorting protein PEP5 \\
\hline HSP04-13 & PGTG_17543 & $62 \%$ & 23.72100 & Um_02189 & Hypothetical protein \\
\hline HSP04-14 & PGTG_17537/8 & $38 \%$ & - & - & Predicted protein \\
\hline
\end{tabular}

* Pgt gene features indicate gene nUmber assigned by the Broad institute during assembly (http://www.broadinstitute.org/annotation/genome/puccinia_group/ verified September 28, 2012). Two nUmbers indicate different scaffolds, as highlighted in Figure 1.

** Mlp gene features are indicated by scaffold nUmber; gene nUmber as assigned by the Joint Genome Initiative at the Department of Energy (http://genomeportal. jgi-psf.org/Mellp1/Mellp1.home.html verified September 28, 2012). 


\begin{abstract}
A
Pt HSP02-4 1 MQF F TA I S L VA L S S GV TGK E I A VY DT L SV T S P S G S S YWV Q F S T N T I AWA 50 PGTG_3708 1 MQF Y TA LLG LVA L S S GV T. . . . . A L S I T S P S G S S YWV QF S T N T I A - 40

Pt HSP02-4 51 L S S G D P T S V S I Q I V N P T NK Q F N G P F S I A E Y V PA A KMIS Y D V T N V Q L I V G D G 100 PGTG_3708 $41 \ldots . . . . . C$ I Q I I N P T NK Q F N G P F S I A E Y V PAA K K S Y D V T N V Q L I I A D G 81

Pt HSP02-4 101 Y Q V Q F V S P L N T Q V LA T S A P F S V KV S G TP EA QV T Y P P T H D SA S - - - N S S 147 PGTG_3708 82 Y E V Q F V N P L N N TEVYA T SA P F S V K T S G TA PA QV T Y A P G T H E S S S S N N S S 131

Pt HSP02-4 148 S N S T S S S N S T S S H P D I N G N S F K N N G T A NA N A K SA S V R A A A V P SMA VFA I G 197

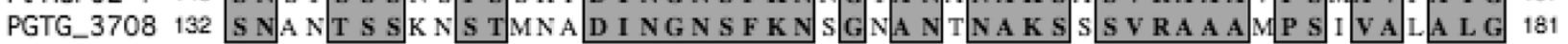

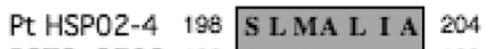

PGTG_3708 182 S L C A L V A 188

\title{
B
}

Pt HSP02-5

PGTG_3709

M. lini HESP-379aa

M. medusae deltoidis HESP-379

M. laricis-populina 70587

U. maydis UM01555

1 MRF L N L F S LAG LTA SAA A F T I NS P - SA S S YWV Q FA T N T I AW S NAP NDS P 49 1 MR SL N L L I S L A G L I A S A A A F T I N S P - S A S S YWV Q F A T N T I A W T NA P N D S P 49 1 MR TSA L L T G LVS LA A S S LA F TV NGP - S A S S YWV Q F S T N T I SW T Q G S G D P P 49 1 MR TS TLL T G L X S LA A S S LA F TV NG P - S A S S YWV Q F S T N T I SWW S T G S G D P P 49 1 MR T SA Fl T G LV S LA A S S LA F TV NGP.SAAS YWV Q F ST N T I SW S QG S G D P P 49

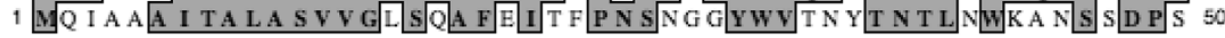

Pt HSP02-5

PGTG_3709

M. lini HESP-379aa

M. medusae deltoidis HESP-379

M. laricis-populina 70587

U. maydis UM01555

50 Q V TL Q I V N S NH T L L NGVF S I A EYVPAA L EA Y TV TNV TLVVA DGY QV QMVN 99

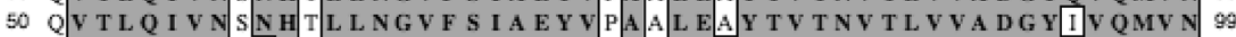
50 V|V S L Q I I N P SK N L L NGA F S I A E Y VKA SL E S Y TV T NV T L L V G D G Y QV QMV N 99

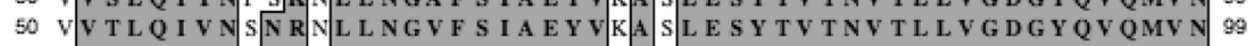
50 VV S L Q I V N P N H N L L NGA F S I A E Y V K A S L E S Y TV T NV TL LV G D G Y QV QMV N 99

Pt HSP02-5

PGTG_3709

M. lini HESP-379aa

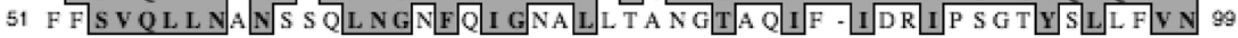

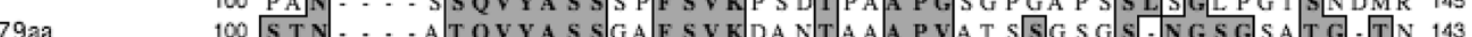

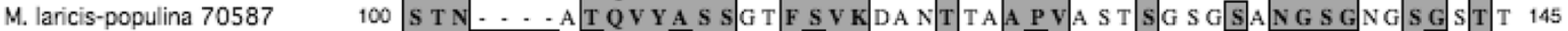

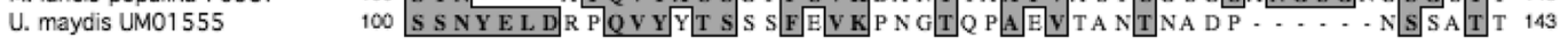

Pt HSP02-5

PGTG_3709

M. lini HESP-379aa

M. medusae deltoidis HESP-379

M. laricis-populina 70587

U. maydis UM01555

146 NMT GMSGMPGSATNGR P GNTT GFNNNSN NGTANSNAR DA SSVYLF SFA 195

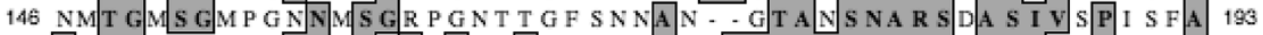

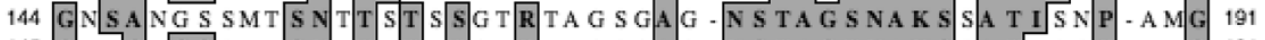

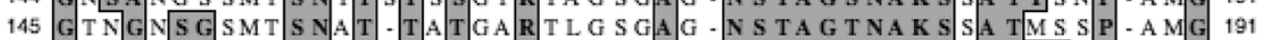
146 G T N G N S G S T T S N T T S T S S G A R T T G S GA G N N S TA G S NA K S SA T I L S P - A M G 193 144 A A T G S A T A T L S SAT G S STS R P S N G S S N . . . S S S SM I Q G ST VA V V G S L V 189

\section{Pt HSP02-5}

PGTG_3709

196 T WS IVA S A I G F V T L 200

194 V L S V V A S A I GLA T L 207

M. lini HESP-379aa 192 L L T V S L L A A I G F A S L 205

M. medusae deltoidis HESP-379 192 L L T V S L A A M G F V S L 205

$\begin{array}{llllllll}\text { M. laricis-populina } 70587 & 194 & \text { LF F T V } & \text { L A A I G F A S L } & 207\end{array}$

U. maydis UM01555 $190 \mathrm{~S} / \mathrm{A} / \mathrm{V} \mathrm{L} \mathrm{G}$ L G A G L L

Figure 1 ClustalW alignments of secreted proteins coded on BAC PtHSP02. A) PtHSP02-4 aligned to a Pgt homolog. B) PtHSP02-5 aligned to homologs from Pgt, Melampsora lini, M. medusae deltoidis, MIp and U. maydis. 


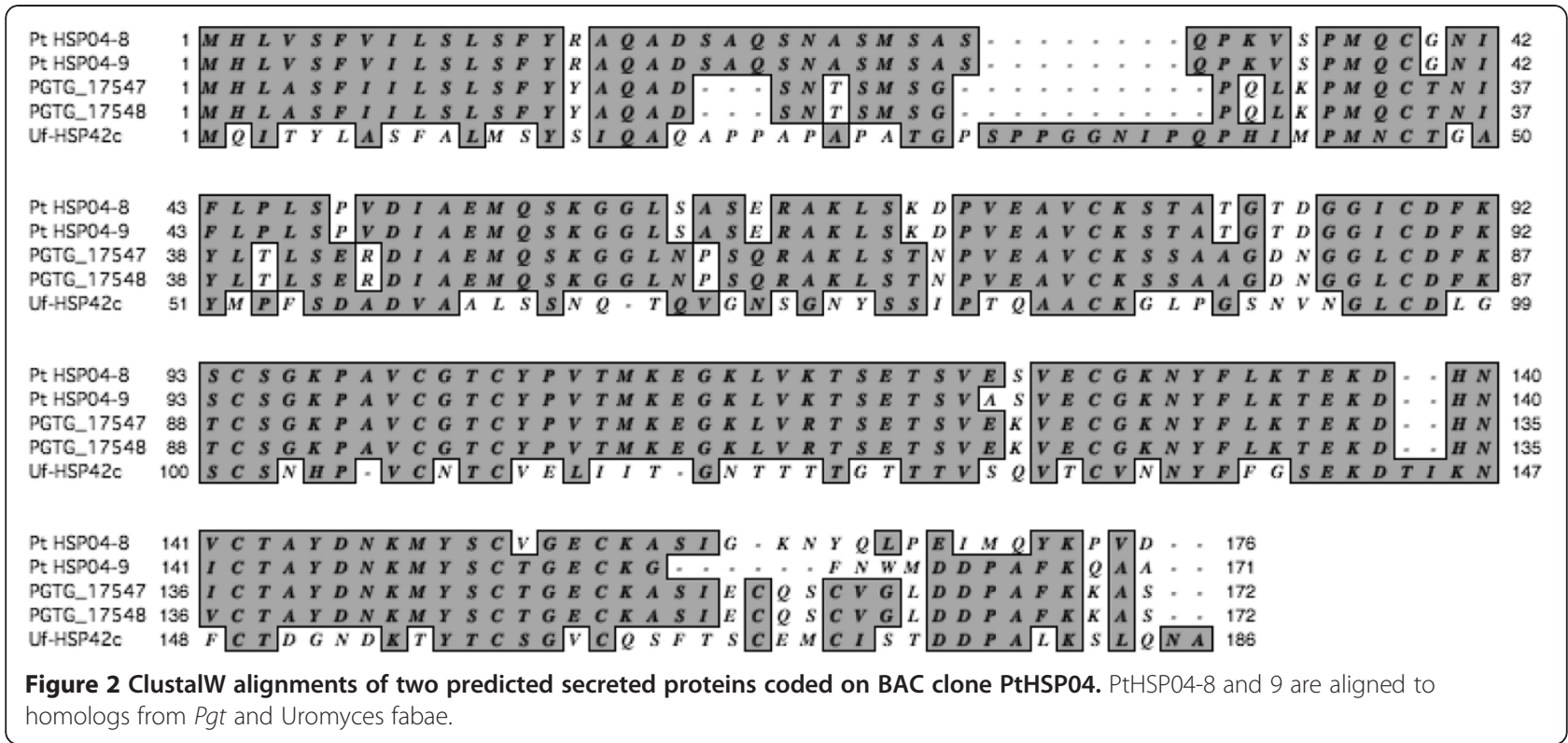

and 9 are $76 \%$ and $71 \%$ identical to PGTG_17547, respectively (Figure 2, Table 1).

\section{Repetitive elements and repeated sequences}

Each BAC was evaluated for repeat elements by using REPBASE against Pgt, Pt and Pst genomes. Complete and incomplete terminal inverted repeats (TIR), LTRs, Copia, Gypsy, Mariner, Mutator, Harbinger, Helitron, hAT, and DNA transposons were found. (Additional file 1: Tables S1 and S2). Major insertions are represented in Figure 1. Copia elements were found inserted within Gypsy elements in Pt1F16 and PtHSP02. PtHSP02 and PtHSP04 also had localization of LTRs.

\section{Synteny}

To investigate whether the high number of candidate orthologs with Pgt maintained the same gene order, the $P t$ BAC sequences were aligned to the available Pgt contig sequences. Figure 3 graphically represents the location along each BAC clone of Pt ORFs with EST sequence or protein homology support. The majority of Pt1F16 aligned to the 325,000 bp to 415,000 bp region of Pgt scaffold (SC) 40 but also to the 5,000 to 65,000 bp region of PgtSC110. PgtSC40 and PgtSC110 could either represent the two Pgt haplotypes or a duplication of this region in the genome. Overall, gene order was maintained in both scaffolds. As previously noted, eight of the Pt1F16 ORFs aligned to homologs in Pgt but Pt1F16-1 to 3 were found only on PgtSC40 (Table 1, Figure 3A). Pt1F16-1 aligned to PGTG_12990 $85 \mathrm{~kb}$ upstream in SC40 of PGTG_13012 whereas Pt1F16-2 and 3 were similarly spaced as their counterparts on this Pgt SC. Between Pt1F16-4 and 5, four retrotransposons were found, of which one was similar to a retroelement in PgtSC110. No mobile elements were found in this region on PgtSC40. PtRAD18 (Pt1F16-7) is a single ORF while Pt1F16-8 aligned to an ORF corresponding a cysteine rich SCP family protein in both SCs of Pgt.

PtHSP02 aligned to a single scaffold, PgtSC7 (Figure 3B). A second haplotype was not detected as the Pgt assembly represents most loci with a single sequence [6]. Nine Pt ORFs could be aligned to homologs on PgtSC7 (position $1,135,000$ to $1,280,000$ ). As with the other BAC clones, gene order was generally maintained. However, PtHSP02-1 and PtHSP02-2 were found embedded between retroelements and LTRs. While PtHSP02-1 aligned to two fragments on PgtSC7, PtHSP02-2 was $48 \%$ homologous to a gene on PgtSC15 elsewhere in the genome. The remaining genes in PtHSP02 were in the same order as on PgtSC7, except a large insertion of approximately $70 \mathrm{kB}$ of DNA, including sequence similar to mobile elements, was found between PGTG_03709 and PGTG_03708 on PgtSC7. Additional PgtSC7 DNA insertions were evident within this gene cluster whereas the $P t$ homologs were packed in a tighter arrangement. Across this region, a higher number of retrotransposon elements were found on PtHSP02 (Additional file 1: Table S1).

PtHSP04 aligned to at least six regions within the Pgt genome and represents the least syntenic sequence amongst the three BAC clones (Figure 3C). PtHSP04-1 and 2 were found on PgtSC84, however, there were several repeat elements within both the $P t$ and $P g t$ regions. PtHSP04-3 appeared to be a fragmented ORF because a single homologous ORF was found on PgtSC35. PtHSP04-4 and 5 were found on two separate scaffolds, PgtSC4 and PgtSC48, respectively. PtHSP-6, 7, 
A

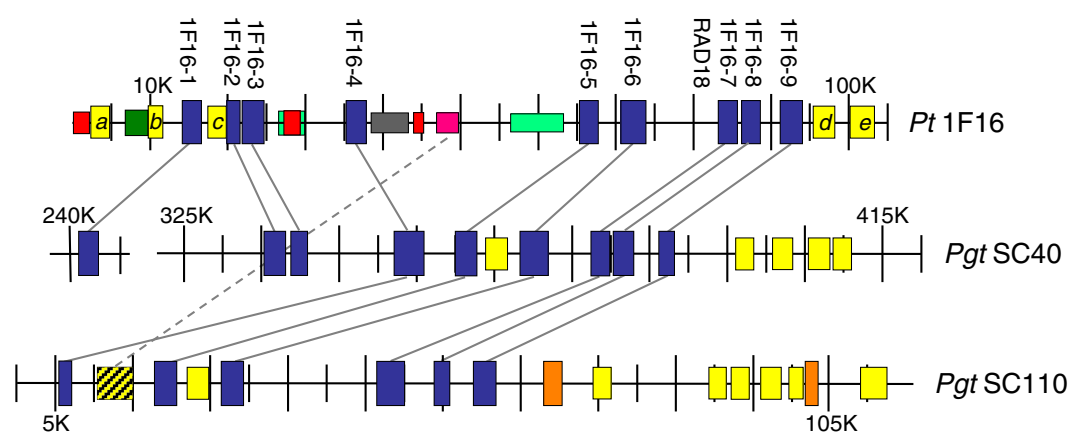

B
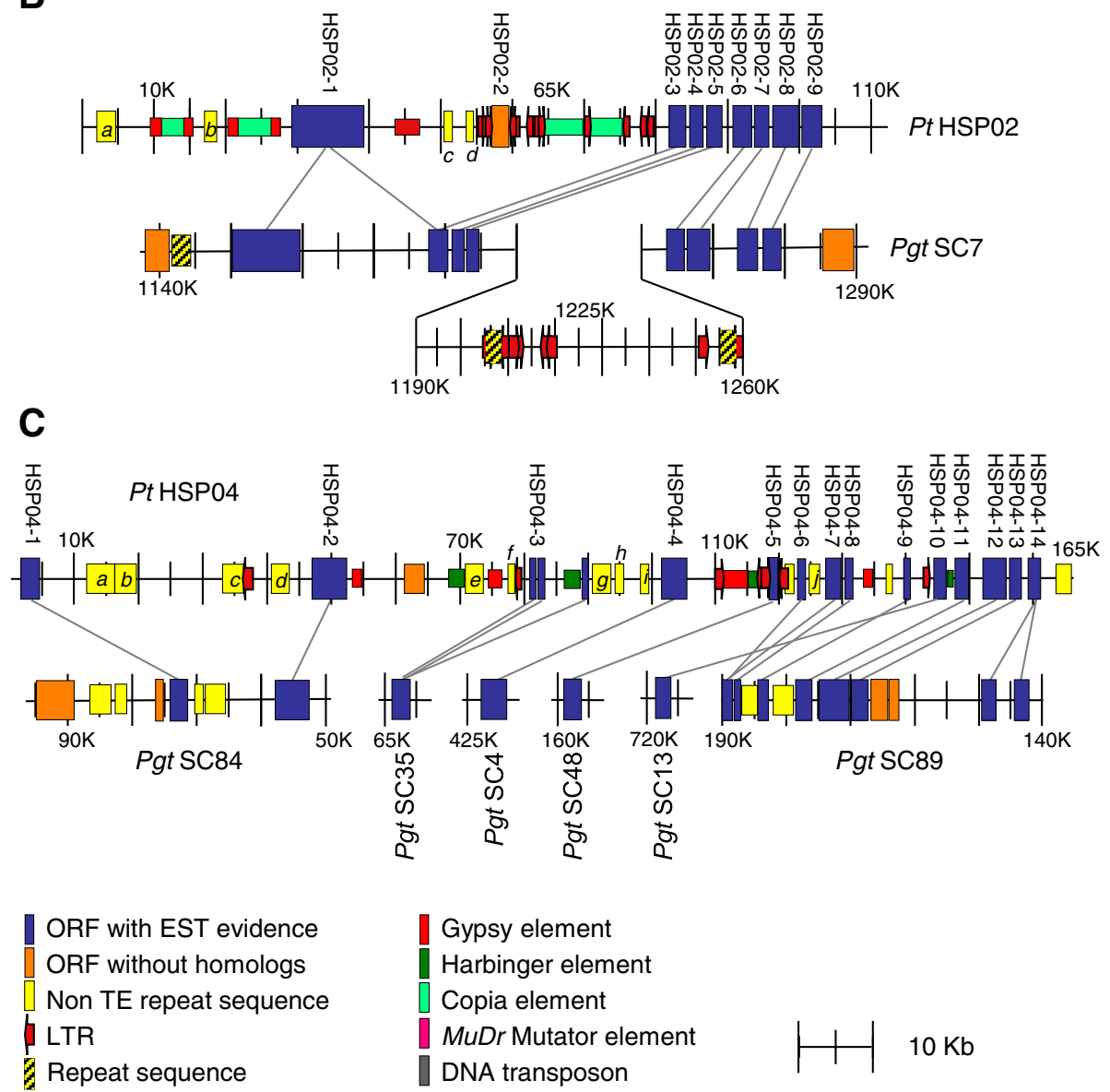

Figure 3 Graphical representation of three BAC clones from P. triticina Pt1F16 (A), PtHSP02 (B) and PtHSP04 (C) and their synteny to super contigs (SC) of $P$. graminis tritici (Pgt). Lines connect homologs between genomes.

8, and 9 have homologs on Pgt SC89 in the same order and similar gene distance (conserved micro-synteny). PtHSP04-10, flanked by an LTR and Harbinger element, does not have a homolog on PgtSC89, but on PgtSC13. Microsynteny of PtHSP04-11, 12, and 13 to Pgt is maintained. PtHSP04-14 is a single copy gene in $P t$ but is repeated in Pgt. between BAC positions 60,000 and 125,000 there are a high number repeat elements.
One of the most interesting sets of sequences were $P t$ ORFs for which numerous homologous copies were found in the Pgt genome but were not classified as typical mobile elements (identified by small letters in Figure 3; Table 2). Twenty of these ORFs had repeats in the Pgt genome numbering from 19 to 474 . Table 2 lists the conserved amino acid domains, if present, in each of the ORFs and the percent identity, which. ranged from 
Table 2 Detailed analysis of non-transposable element, repeated sequences in three $P$. triticina BAC clones

\begin{tabular}{|c|c|c|c|c|c|c|c|}
\hline ORF & Size bp & Pgt repeats & Conserved domain & $\%$ Ident & $\operatorname{Exp}^{*}$ & Dominant peptide & Notes \\
\hline 1F16-a & 757 & 35 & $194-443$ & 51 & no & $9.2 \%$ Lys & 216-252-40.3\% CI Winged helix DNA/RNA binding \\
\hline $1 F 16-b$ & 458 & 98 & $97-458$ & 40 & no & $11.8 \%$ Lys & Highly helical \\
\hline $1 F 16-\mathrm{C}$ & 462 & 98 & all & 40 & no & $13.2 \%$ Lys & 6-91-60.3\% Cl ubiquitin ligase \\
\hline \multirow[t]{2}{*}{$1 F-16-d$} & 489 & 44 & 344-485 & 48 & no & $10.8 \%$ Lys & 3 alpha helices and 7 beta sheets in conserved domain \\
\hline & & & & & & $13.0 \% \operatorname{Ser}$ & \\
\hline 1F16-f & 651 & 80 & $51-245$ & 74 & yes & $9.2 \%$ Lys & 38-163-38.7\% Cl oxidoreductase \\
\hline HSPO2-a & 658 & 19 & all & 31 & no & $9.7 \%$ Lys & \\
\hline \multirow[t]{2}{*}{$\mathrm{HSPO2-b}$} & 299 & 80 & $35-94$ & 68 & no & $9.4 \%$ Lys & $32-73-80 \% \mathrm{Cl}$ metal binding protein \\
\hline & & & & & & $11.7 \%$ Ser & $145-256-80 \% \mathrm{Cl}$ protease hydrolase inhibitor \\
\hline \multirow[t]{2}{*}{ HSPO2-C } & 252 & 50 & $33-127$ & 52 & yes & $11.1 \%$ Lys & 33-95 53\% Cl DNA binding domain \\
\hline & & & & & & $10.7 \%$ Glu & \\
\hline \multirow[t]{3}{*}{ HSPO2 } & 243 & 35 & all & & yes & 11.9\% Ala & Alignment in Pgt are to DNA, not protein \\
\hline & & & & & & $13.6 \%$ Ser & \\
\hline & & & & & & $11.5 \% \mathrm{Thr}$ & \\
\hline HSPO4-a & 952 & 74 & $256-470$ & 48 & no & $9.9 \%$ Ala & \\
\hline HSPO4-b & 484 & 76 & $300-454$ & 74 & no & none & \\
\hline HSPO4-C & 442 & 69 & all & 34 & yes & 9.0\% Lys & \\
\hline HSPO4-d & 679 & 81 & $10-351$ & 68 & no & 9.3\% Lys & 11 alpha helices in conserved region \\
\hline HSPO4-e & 420 & 131 & $55-386$ & 55 & yes & $9.5 \%$ ala & 216-388-51\% identical in Mlp \\
\hline HSPO4-f & 262 & 474 & 20-189 & 44 & no & $11.5 \%$ ser & EST sequence hits \\
\hline \multirow[t]{2}{*}{ HSPO4-g } & 543 & 96 & all & 69 & yes & $11.4 \%$ Lys & Highly helical \\
\hline & & & & & & $9.0 \%$ ser & \\
\hline HSPO4-h & 262 & 66 & $199-258$ & 65 & yes & $12.6 \%$ Lys & P-loop NTPase/DEAD box \\
\hline \multirow[t]{2}{*}{ HSPO4-i } & 326 & 20 & $127-242$ & 34 & yes & $12.8 \%$ Lys & Highly helical \\
\hline & & & & & & $11.0 \% \mathrm{Glu}$ & \\
\hline \multirow[t]{2}{*}{ HSP04-j } & 309 & 69 & 191-303 & 35 & no & 9.7\% Lys & 2-191-99.7\% Cl Recombinant DNA binding/ RAD54 like \\
\hline & & & & & & $10.7 \%$ Ser & \\
\hline
\end{tabular}

Each was evaluated for number of repeated homologs in the Pgt genome, region of conservation, alignment identity, expression in infected tissue, the dominant peptides, and their best detected fit to a protein structural model.

* Exp - expression in infected tissue 6 dpi.

** PHYRE 2.0 confidence interval (Cl) of protein segment matching a structural model with the listed function [35]. 
34-74\%. Each ORF was compared to an RNAseq cDNA library of Pt-infected leaf tissue (Fellers and Bruce, unpublished) and nine aligned to the experimental cDNA sequences. The predicted proteins were analyzed for peptide content and most had an abundance of Lys, which is suggestive of helical structures. Each of the proteins was also compared to the PHYRE 2.0 structural data base [35] resulting in seven that revealed regions that aligned, with confidence, to known structures. The first 191 peptides of PtHSP04-j had a structure similar to RAD54, with $99.7 \%$ confidence. Of note, PtHSP04-e was expressed and was 51\% identical to a protein in $M l p$.

\section{Discussion}

This study was performed to look at three regions of the Pt genome that were hypothesized to be under selection pressure because of the presence of putative secreted proteins or loci associated with avirulence. To begin with, gene order is conserved between the Pt BACs and Pgt. However, there is a wide range of protein conservation. A previous comparison of ESTs of Pt and Pgt found a similar level of variation in sequence, but only $40 \%$ of the Pt EST unigenes had orthologs in Pgt [32]. Many genes were likely missing in the unigene set because of the difficulty of sampling other $P t$ life stages to sufficient depth, affecting the percentage. Nevertheless, within the BAC clones, many protein identities were supported by ESTs and similar sequence variation was present [32]. Some proteins were highly conserved between the two wheat rust fungi and had homologs in $M l p$ and $U m$ [36].

The three genes used for identifying the BACs were of most interest, in particular, the amount of variation within the sequence. PgtRAD18 had been associated with an avirulence locus in Pgt [30]. PtRAD18 protein length is relatively similar but the sequence has diverged from the PgtRAD18 with only 56\% identity. Structurally, PtRAD18 is still closely associated with a predicted secreted protein. Pt has two genes similar to HESP-379 from M. lini [16]. Two indels in PtHSP02-4 suggest a recombination event or splicing difference evolved since the two species diverged, while the sequence differences in the C-terminus of PtHSP02-5 suggest that this region could be very variable. PtHSP04 contained a four-gene locus predicted to code for secreted proteins. Two of them are unique while two are recently duplicated paralogs. Secreted proteins are believed to be most variable amongst fungal proteins because they are under the highest selection pressure to avoid recognition by the host $[16,19,37]$. At least with these examples, It can be said that sequence variation, recombination, and duplication are driving the changes in these proteins.

Numerous fungal genomes have recently been generated, analyzed, and published. Now comparisons can be made to find core gene families associated with specific life styles and cycles. In an extensive comparison, Duplessis et al. [6] identified core conserved genes needed for biotrophic life in both rust species. It appears that PtHSP02-6 may be one of those genes. PtHSP02-6 aligns with a G-protein beta subunit (GPBS) and no peptide differences were found between $P t$ and Pgt. Furthermore, there is little difference between $P t$ and $M l p$ suggesting that this protein is under strong purifying selection in rusts. Yet, the genes flanking PtHSP02-6 are relatively conserved indicating strong selection and the importance of this gene. In Verticillium dahliae, mutations in GPBS had reduced virulence, increased microsclerotia and conidiation and decreased ethylene production [38]. GPBS is also involved in similar functions in F. oxysporum [39]. In M. grisea, GPBS mutants could not form appresorium, and hyphae could not penetrate and grow in rice leaves [40]. The authors also showed that by over expressing GPBS in the fungus, appressorium could form on a hydrophillic surfaces suggesting that GPBS is necessary for control of surface recognition, growth and appressorium formation [40]. Surface recognition and appressorium formation are the key to rust fungal establishment. This suggests that PtHSP02-6 is indispensable for the biotrophic lifecycle and could be a regulating link in pathogenicity.

A strong correlation between genome size and repetitive element content has been found for many fungal genomes. Genome expansion is significant between Pt and Pgt, even though they are both closely related and are both dikaryotic. The assembled genome for Pgt is $89 \mathrm{Mb}$ [6] while $P t$ is currently estimated to be $135 \mathrm{Mb}$ (Broad Institute). The sequence analysis of the three BAC clones gives some indication on why the $P t$ genome may be larger than the Pgt genome. Pt1F16 had the least mobile element complexity, but had Gypsy elements within Copia elements, as did PtHSP02. PtHSP02 also harbored numerous TEs and LTRs in the region between PtHSP02-1 and 3. Meanwhile, PtHSP04 contains more non-TE repeat ORFs, its homologous genes are scattered across $P g t$ scaffolds, and its sequence reveals recombination and/or transposition events disrupting syntenic genes. There is also evidence of gene movement by active elements. PtHSP02-2 was directly flanked by LTRs and was not found in PgtSC7, PtHSP04-5 was also flanked by LTRs and could be found in PgtSC48, and PtHSP04-10 only had a single LTR flanking it, but was flanked on the opposite side by a partial Harbinger element. It is possible that since these regions are in repetitive sequence there are assembly errors in Pgt, however, each Pgt homolog are in high confidence scaffolds.

Most surprising are the non-transposable element, repeated sequences found in the Pt BACs (Table 2). Each 
had homologs throughout the Pgt genome. Most had conserved domains that were maintained, while flanking sequences were greatly diverged. Many were high in Lys suggesting a helix protein structure. Some are expressed, based on the presence of an aligning EST, and have homologs in Mlp, suggesting an importance. The helical nature of these proteins would suggest their involvement as nucleotide binding elements. $P t$ has five different spore types in its lifecycle involving two different hosts requiring a significant level of cell modifications and cell types. Sequences like these have not been described before and could represent undiscovered elements in the disease cycle.

This work has shown significant genome synteny between two closely related wheat rust fungi. Gene sequences confirmed previous findings of the existence of EST sequence variation between Pt and Pgt. Various levels of homologies are present, but many of the genes are diverging in a manner that is species specific [32]. Both genomes have a significant amount of mobile elements. Some TE copies are conserved between the two species suggesting ancestral insertion. The insertion of TE sequences helps explain genome expansion, and their insertion near secreted protein genes may alter their regulation or cause their duplication and spread or deletion. Most surprising was the presence of small predicted non-TE genes with numerous homologs in Pgt. As many of the small repeated sequences are highly helical in predicted structure, one could suggest they are involved in DNA binding and regulation. Further work is needed to determine when they are expressed and at what stage of the life cycle. When analysis of the $P t$ and Pst genomes has been concluded, it can be determined if the repeated nature of these predicted genes is maintained within the wheat rust fungi.

\section{Methods \\ Pt BAC library}

Total genomic DNA for the BAC library construction was isolated from P. triticina (Pt) Race1, BBBD [41] urediniospores collected from susceptible wheat (Triticum aestivum L.) cultivar Thatcher. Spores were increased on plants spray-inoculated with a urediniospore suspension in light mineral oil (Soltrol 170 isoparaffin, Conoco-Phillips Chemical Co, Borger TX). The oil was allowed to evaporate for $30 \mathrm{~min}$, then plants were moved to a dark dew chamber at $20^{\circ} \mathrm{C}$ and $100 \%$ relative humidity for 24 hrs for urediniospore germination and appressorium formation. Plants were grown in a growth chamber under 16 -hour day at $20^{\circ} \mathrm{C}$. After 10 days, urediniospores were collected and germinated by densely dusting them over sterile water in dishes for $8 \mathrm{hrs}$ using a volatile nonanol solution $(1.56 \mu \mathrm{l}$ nonanol (Sigma-Aldrich, St. Louis MO), $1 \mathrm{ml}$ acetone, $19 \mathrm{ml}$ of $\mathrm{ddH}_{2} \mathrm{O}$ ) spotted on filter paper which was suspended in the lids to stimulate urediniospore germination under crowded conditions. The BAC library was constructed by BioS\&T (Montreal, Quebec, Canada; www.biost.com). In brief, nuclei were isolated from collected germinated urediniospores and embedded in $1 \%$ low melting point agarose plugs. Total genomic DNA embedded in the plugs was partially digested with HindIII, separated by electrophoresis by pulse field gel electrophoresis, and the $100-200 \mathrm{~kb}$ region was isolated. After electro-elution and dialysis, the DNA fragments were cloned into the HindIII site of BAC vector pIndogoBAC5 (Epicenter Technologies, Madison, WI) and propagated in E. coli DH10B (Life Technologies, Grand Island, NY).

\section{BAC clone selection and sequencing}

The resulting BAC library of 15,360 individual clones was arrayed on nylon membranes. After colony lysis, DNA was bound to the membranes using standard procedures [41]. BAC filters were probed to identify clones for sequencing. Several candidate fragments were selected as probes. The Sfi1 insert from a Pt cDNA clone, PT0313.J16.C21 (GenBank accession GR497566; [32]) was labeled with $\alpha \mathrm{P}^{32}$-dCTP using a random primer labeling kit (GE Heathcare, Pittsburg, PA). Positive BAC clones were verified by PCR using primers Forward 5'-AGCTCTTCAC ACGATTCC and Reverse 5'-ATCTTGGCATTGAGC ATC. The second probe, SP02, was amplified from $P t$ cDNA clone PT0061b.D10.TB (GenBank accession EC400508) by PCR using primers Forward 5'- CTTTCTA GACCTAGGCAACTTAACAC and Reverse 5'- GCGCC ATGGACTAGTTGAAGAGGGA. The third probe, SP04 was amplified from cDNA clone, PT0131d.B10.BR (GenBank accession EC414978) using PCR primers Forward 5'-CACGAGGGGAACCGATGGGGGT and Reverse 5'-TGGGTTGGTAAACTATTAATGTGCAC. Southern hybridizations were as described [41]

Selected BAC clones were sent as a stab culture to the Genome Center at Washington University, St. Louis, MO. BAC clones were cultured, subcloned, shot gun sequenced, and assembled (Washington University Genome Center, St. Louis, MO). Gene calls were made using FGENESH with gene models specific to Puccinia (http://linux1. softberry.com/berry.phtml;). BAC clone gene predictions were compared to Pgt, Mlp and Um genomic resources (http://www.broadinstitute.org/annotation/genome/puccinia group/Blast.html; http://genomeportal.jgi-psf.org/Mellp1/ Mellp1.home.html verified May 7, 2012 and http://www. broadinstitute.org/annotation/genome/ustilago_maydis) using the BLASTN and BLASTX algorithms with settings of $\mathrm{E}$ value $=1 \mathrm{e}^{-3}$, Matrix $=$ BLOSUM62, and gapped alignment. Repeats were identified using fungaldb of RepBase 17.04 [42], containing the repeats of Pt, Pgt and Pst. Long terminal repeats (LTR) were determined by LTR_Finder [43] (e.g., red arrows in Figure 3). 


\begin{abstract}
Mention of a trademark of a proprietary product does not constitute a guarantee of warranty of the product by the United States Department of Agriculture, and does not imply its approval to the exclusion of other products that may also be suitable. USDA is an equal opportunity provider and employer.
\end{abstract}

\section{Additional file}

Additional file 1: Table S1. Repeat elements found in three $P$. triticina BAC clones. BAC sequences were compared to RePBASE, a database containing characterized repeat elements from $P$. triticina $(P t), P$. graminis tritici $(P g t)$, and $P$. striiformis tritici (Pst). Repeats are listed by position in the respective Pt BAC clone, DNA strand, and the species specific element. Table S2. Description of matching repeats, type of element and which rust fungus they are from.

\section{Abbreviations}

BAC: Bacterial artificial chromosome; Pt: Puccinia triticina; Pgt: P. graminis tritici; Pst: P. stiiformis f.sp tritici; Mlp: Melampsora larici-populina; bp: Base pair; HESP: Haustoria expressed secreted protein.

\section{Competing interests}

The authors declare that they have no competing interests.

\section{Authors' contributions}

GB and JPF conceived the study. GB provided the DNA and constructed the BAC library. BMS and RL designed the primers and isolated the BACs. JPF sequenced the BACs, analyzed the sequence and made gene calls along with MB. CAC analyzed the sequence for repetitive sequence. LS provided the probes for RAD18. JPF, GB, and CAC wrote the manuscript. All authors read and approved the final manuscript.

\section{Acknowledgements}

The authors would like to thank Drs. Robert Bowden and Randy Dinkens for their comments in the preparation of the manuscript. JPF is supported by USDA-ARS CRIS 5430-21000-005-00.

\section{Author details}

'USDA-ARS, Hard Winter Wheat Genetics Research Unit, Department of Plant Pathology, Manhattan, KS 66506, USA. ${ }^{2}$ Agriculture \& Agri-Food Canada, Pacific Agri-Food Research Centre, Summerland, BC VOH 1Z0, Canada. ${ }^{3}$ Broad Institute, 7 Cambridge Center, Cambridge, MA 02142, UK. ${ }^{4}$ USDA-ARS, Cereal Disease Laboratory, 1551 Lindig, St. Paul, MN 55108, UK.

Received: 28 September 2012 Accepted: 11 January 2013

Published: 29 January 2013

\section{References}

1. Cummins GB, Hiratsuka Y: Illustrated genera of rust fungi. 3rd edition. St Paul: American Phytophatological Society; 2003:225.

2. Liu JQ, Kolmer JA: Molecular and virulence diversity and linkage disequilibria in asexual and sexual populations of the wheat leaf rust fungus, puccinia recondita. Genome 1998, 41:832-840.

3. Uppalapati S, Ishiga Y, Doraiswamy V, Bedair M, Mittal S, Chen J, Nakashima J, Tang Y, Tadege M, Ratet P, Chen R, Schultheiss H, Mysore KS: Loss of abaxial leaf epicutaular wax in Medicago truncatula irg1/palm1 mutants results in reduced spore differentiation of anthracnose and nonhoast rust pathogens. Plant Cell 2012, 24(1):353-370.

4. Harder $\mathrm{JH}$ : Developmental ultrastructure of hyphae and spores. In The cereal rusts, Vol I. Edited by Bushnell WR, Roelfs AP. Orlando, Florida: Academic; 1984:333-373.

5. Bolton MD, Kolmer JA, Garvin DF: Wheat leaf rust caused by Puccinia triticina. Mol Plant Path 2008, 9(5):563-575.

6. Duplessis S, Cuomo C, Lin Y-C, Aerts A, Tisserant E, Veneault-Fourrey C, Joly DL, Hacquard S, Amselem J, Cantarel BL, Chiu R, Coutinho PM, Feaue N, Field M, Frey P, Gelhaye E, Goldberg J, Grabherr MG, Kodira CD, Kohler A, Kües U, Lindquist EA, Lucas SM, Mago R, Mauceli E, Morin E, Murat C,
Pangilinan JL, Park R, Pearson M, Quesneville H, Rouhier N, Sakthikumar S, Salamov AA, Schmutz J, Selles B, Shapiro H, Tanguay P, Tuskan GA, Henrissat $B$, Van de Peer Y, Rouzéc P, Ellis JG, Dodds PN, Scheinh JE, Zhong S, Hameline RC, Grigoriev IV, Szabo LS, Martin F: Obligate biotrophy features unraveled by the genomic analysis of rust fungi. Proc Nat Acad Sci 2011, 108:9166-9171.

7. Kasuga T, Kozanitas M, Bui M, Hüberli D, Rizzo DM, Garbelotto M: Phenotypic diversification is associated with host-induced transposon derepression in the sudden oak death pathogen Phytophthora ramorum. PLoS One 2012, 7(4):e34728.

8. Kang S, Lebrun MH, Farrall L, Valent B: Gain of virulence caused by insertion of a Pot3 transposon in a Magnaporthe grisea avirulence gene. MPMI 2001, 14:671-674.

9. Gout L, Fudal I, Kuhn M, Blaise F, Eckert M, Cattolico L, Balesdent M-H, Rouxel T: Lost in the middle of nowhere: the AvrLm1 avirulence gene of the Dithideomycete Leptoshaeria maculans. Molec Microb 2006, 60(1):67-80.

10. Ma L, van der Does C, Borkovich KA, Coleman JJ, Daboussi M, et al: Comparitive genomics reveals mobile pathogenicity chromosomes in Fusarium. Nature 2010, 64:367-373.

11. Rep M, Kistler HC: The genomic organization of plant pathogenicity in Fusarium species. Curr Opinion in Plant Biol 2011, 13(4):420-426.

12. Kämper J, Kahmann R, Bölker M, Ma $\sqcup$, Brefort T, Saville BJ, Banuett F, Kronstad JW, Gold SE, Müller O, Perlin MH, Wösten HA, de Vries R, RuizHerrera J, Reynaga-Peña CG, Snetselaar K, McCann M, Pérez-Martín J, Feldbrügge M, Basse CW, Steinberg G, Ibeas Jl, Holloman W, Guzman P, Farman M, Stajich JE, Sentandreu R, González-Prieto JM, Kennell JC, Molina L, Schirawski J, Mendoza-Mendoza A, Greilinger D, Münch K, Rössel N, Scherer M, Vranes M, Ladendorf O, Vincon V, Fuchs U, Sandrock B, Meng S, Ho EC, Cahill MJ, Boyce KJ, Klose J, Klosterman SJ, Deelstra HJ, OrtizCastellanos L, Li W, Sanchez-Alonso P, Schreier PH, Häuser-Hahn I, Vaupel M, Koopmann E, Friedrich G, Voss H, Schlüter T, Margolis J, Platt D, Swimmer C, Gnirke A, Chen F, Vysotskaia V, Mannhaupt G, Güldener U, Münsterkötter M, Haase D, Oesterheld M, Mewes HW, Mauceli EW, DeCaprio D, Wade CM, Butler J, Young S, Jaffe DB, Calvo S, Nusbaum C, Galagan J, Birren BW: Insights from the genome of the biotrophic fungal plant pathogen Ustilago maydis. Nature 2006, 444(7115):97-101.

13. Cuomo C, Güldener U, Xu JR, Trail F, Turgeon BG, Di Pietro A, Walton JD, Ma L, Baker SE, Rep M, Adam G, Antoniw J, Baldwin T, Calvo S, Chang Y, DeCaprio D, Gale LR, Gnerre S, Goswami RS, Hammond-Kosack K, Harris LJ, Hilburn K, Kennell JC, Kroken S, Magnuson JK, Mannhaupt G, Mauceli E, Mewes H, Mitterbauer R, Muehlbauer G, Münsterkötter M, Nelson D, O'Donnell K, Ouellet T, Qi W, Quesneville H, Roncero MIG, Seong K, Tetko IV, Urban M, Waalwijk C, Ward TJ, Ao J, Birren BW, Kistler HC: The Fusarium graminearum genome reveals a link between localized polymorphism and pathogen specialization. Science 2007, 317(5843):1400-1402.

14. Dean RA, Talbot NJ, Ebbole DJ, Farman ML, Mitchell TK, Orbach MJ, Thon M, Kulkarni R, Xu JR, Pan H, Read ND, Lee YH, Carbone I, Brown D, Oh YY, Donofrio N, Jeong JS, Soanes DM, Djonovic S, Kolomiets E, Rehmeyer C, Li W, Harding M, Kim S, Lebrun MH, Bohnert H, Coughlan S, Butler J, Calvo S, Ma LJ, Nicol R, Purcell S, Nusbaum C, Galagan JE, Birren BW: The genome sequence of the rice blast fungus Magnaporthe grisea. Nature 2005, 434(7036):980-986.

15. Dodds PN, Lawrence GJ, Catanzariti AM, Teh T, Wang CIA, Ayliffe MA, Kobe $B$, Ellis JG: Direct protein interaction underlies gene-for-gene specificity and coevolution of the flax resistance genes and flax rust avirulence genes. Proc Nat Acad Sci USA 2006, 103:8888-8893.

16. Catanzariti AM, Dodds PN, Lawrence GJ, Ayliffe MA, Ellis JG: Haustorially expressed secreted proteins from flax rust are highly enriched for avirulence elicitors. Plant Cell 2006, 18:243-256.

17. Nirmala J, Drader T, Lawrence PK, Yin C, Hulbert S, Steber CM, Steffenson BJ, Szabo $\sqcup$, von Wettstein $D$, Kleinhofs A: Conerted action of two avirulent spore effectors activates Reaction to Puccinia graminis 1 (Rpg1)-mediated cereal stem rust resistance. Proc Nat Acad Sci USA 2011, 108(35):14676-14681.

18. Spanu PD, Abbott JC, Amselem J, Burgis TA, Soanes DM, Stüber K, Ver Loren Van Themaat E, Brown JK, Butcher SA, Gurr SJ, Lebrun MH, Ridout CJ, Schulze-Lefert P, Talbot NJ, Ahmadinejad N, Ametz C, Barton GR, Benjdia M, Bidzinski P, Bindschedler LV, Both M, Brewer MT, Cadle-Davidson L, CadleDavidson MM, Collemare J, Cramer R, Frenkel O, Godfrey D, Harriman J, Hoede C, King BC, Klages S, Kleemann J, Knoll D, Koti PS, Kreplak J, LópezRuiz FJ, Lu X, Maekawa T, Mahanil S, Micali C, Milgroom MG, Montana G, Noir S, O'Connell RJ, Oberhaensli S, Parlange F, Pedersen C, Quesneville H, 
Reinhardt R, Rott M, Sacristán S, Schmidt SM, Schön M, Skamnioti P, Sommer H, Stephens A, Takahara H, Thordal-Christensen H, Vigouroux M, Wessling R, Wicker T, Panstruga R: Genome expansion and gene loss in powdery mildew fungi reveal tradeoffs in extreme parasitism. Science 2010, 330(6010):1543-15436.

19. Schirawski J, Mannhaupt G, Münch K, Brefort T, Schipper K, Doehlemann G, Stasio MD, Rössel N, Mendoza-Mendoza A, Pester D, Müller O, Winterberg B, Meyer E, Ghareeb H, Wollenbert T, Münsterkötter M, Wong P, Walter M, Stukenbrock E, Güldener U, Kahmann R: Pathogenicity determinants in smut fungi revealed by genome comparison. Science 2010, 330:1546-1548.

20. Jin Y, Szabo LJ, Carson M: Century-old mystery of Puccinia striiformis life history solved with the identification of Berberis as an alternate host. Phytopathology 2010, 100:432-435.

21. Saari EE, Young HC, Kernkamp MF: Infection of North American Thalictrum ssp. with Puccinia recondita f.sp. tritici. Phytopathology 1968, 58:939-943.

22. Chester KS: The Nature And Prevention Of The Cereal Rusts As Exemplified In The Leaf Rust Of Wheat. Waltham Mass: Chronica Botanica Co; 1946.

23. Jackson HS, Mains EB: Aecial stage of the orange leaf rust of wheat, Puccinia triticina Eriks. Journal of Agr Res 1921, 22:151-172.

24. Goyeau H, Halkett F, Zapater M, Carlier J, Lannou C: Clonality and host selection in the wheat pathogenic fungus Puccinia triticina. Fungal Genetics and Biol 2007, 44(6):474-483.

25. Kolmer JA, Liu JQ, Sies M: Virulence and molecular polymorphism in Puccinia recondita fsp tritici in Canada. Phytopathology 1995, 85:276-285.

26. Kolmer JA, Ordoñez ME: Genetic differentiation of Puccinia triticina populations in central Asia and the Caucasus. Phytopathology 2007, 97:1141-1149.

27. Ordoñez ME, Kolmer JA: Differentiation of molecular genotypes and virulence phenotypes of Puccinia triticina from common wheat in North America. Phytopathology 2009, 99:750-758.

28. Ordoñez ME, German SE, Kolmer JA: Genetic differentiation within the Puccinia triticina population in South America and comparison with the North American population suggests common ancestry and intercontinental migration. Phytopathology 2010, 100:376-383.

29. Wang X, McCallum B: Fusion body formation, germ tube anastomosis, and nuclear migration during the germination of urediniospores of the wheat leaf rust fungus, Puccinia triticina. Phytopathology 2009, 99(12):1355-1364.

30. Zambino PJ, Kubelik AR, Szabo $\sqcup$ : Gene action and linkage of avirulence genes to DNA markers in the rust fungus Puccinia graminis. Phytopathology 2000, 90:819-826.

31. Hu G, Linning R, McCallum B, Banks T, Cloutier S, Butterfield Y, Liu J, Kirkpatrick R, Stott J, Yang G, Smailus D, Jones S, Marra M, Schein J, Bakkeren G: Generation of a wheat leaf rust, Puccinia triticina, EST database from stage-specific cDNA libraries. Mol Plant Pathol 2007, 8:451-467.

32. Xu J, Linning R, Fellers J, Dickinson M, Zhu W, Antonov I, Joly D, Donaldson ME, Eilam T, Anikster Y, Banks T, Munro S, Mayo M, Wynhoven B, Ali J, Moore R, McCallum B, Borodovsky M, Saville B, Bakkeren G: Gene discovery in EST sequences from the wheat leaf rust fungus Puccinia triticina sexual spores, asexual spores and haustoria, compared to other rust and corn smut fungi. BMC Genomics 2011, 12:161.

33. Link TI, Voegele RT: Secreted proteins of Uromyces fabae: similarities and stage specificity. Mol Plant Pathology 2008, 9(1):59-66.

34. Dong YL, Yin CT, Hulbert S, Chen XM, Kang ZS: Cloning and expression analysis of three secreted protein genes from wheat stripe rust fungus Puccinia striiformis f. sp. tritici. J Microbiol Biotechnol 2011, 27(5):1261-1265.

35. Kelley LA, Sternberg MJE: Protein structure prediction on the web: a case study using the Phyre server. Nat Protoc 2009, 4:363-371.

36. Oberhaensli S, Parlange F, Buchmann JP, Jenny FH, Abbott JC, Burgis TA, Spanu PD, Keller B, Wicker T: Comparative sequence analysis of wheat and barley powdery mildew fungi reveals colinearity, dates of divergence and indicates host-pathogen co-evolution. Fungal Gen Biol 2011, 48:327-334

37. Laurie JD, Ali S, Linning R, Mannhaupt G, Wong P, Güldener U, Münsterkötter M, Link TI, Voegele RT: Secreted proteins of Uromyces fabae: similarities and stage specificity. Mol Plant Pathol 2008, 9:59-66.

38. Tzima AK, Paplomatas EJ, Tsitsigiannis DI, Kang S: The G protein ß subunit controls virulence and multiple growth- and development -related traits in Verticillium dahlia. Fungal Genet Biol 2012, 49(4):271-283.

39. Delgado-Jarana J, Martínez-Rocha AL, Roldán-Rodriguez R, Roncero MI, Di Pietro A: Fusarium oxysporum G-protein beta subunit Fgb1 regulates hyphal growth, development, and virulence through multiple signalling pathways. Fungal Genet Biol 2005, 42(1):61-72.

40. Nishimura M, Park G, Xu JR: The G-beta subunit MGB1 is involved in regulating multiple steps of infection-related morphogenesis in Magnaporthe grisea. Mol Microbiol 2003, 50(1):231-243

41. Sambrook J, Rusell DW: Molecular Cloning: A Laboratory Manual. 3rd edition. Cold Spring Harbor: NY: Cold Spring Harbor Laboratory Press; 2001.

42. Jurka J, Kapitonov W, Pavlicek A, Klonowski P, Kohany O, Walichiewicz J: Repbase Update, a database of eukaryotic repetitive elements. Cytogentic and Genome Res 2005, 110:462-467.

43. Xu Z, Wang H: LTR_FINDER: an efficient tool for the prediciton of full-length LTR retrotransposons. Nucleic Acids Res 2007, 35:W265-W268.

doi:10.1186/1471-2164-14-60

Cite this article as: Fellers et al:: Conserved loci of leaf and stem rust fungi of wheat share synteny interrupted by lineage-specific influx of repeat elements. BMC Genomics 2013 14:60.

\section{Submit your next manuscript to BioMed Central and take full advantage of:}

- Convenient online submission

- Thorough peer review

- No space constraints or color figure charges

- Immediate publication on acceptance

- Inclusion in PubMed, CAS, Scopus and Google Scholar

- Research which is freely available for redistribution 